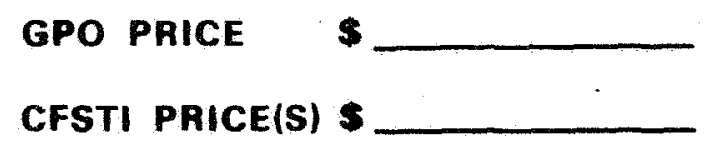

Hard copy $(\mathrm{HC})$

Microfiche (MF)

ff 653 July 65

\title{
Research Center
}

School of Business and Public Administration UNIVERSITY OF MISSOURI, COLUMBIA
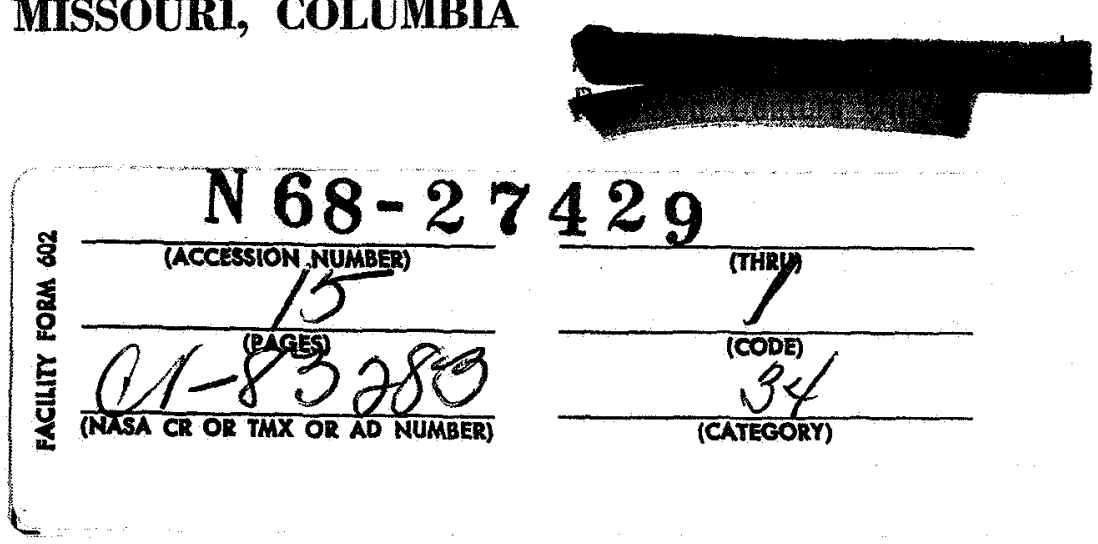


\title{
AN ECONOMIC ANALYSIS OF SPATIAL PATTERNS \\ OF RESEARCH AND DEVELOPMENT IN THE \\ PHARMACEUTICAL INDUSTRY
}

\author{
by
}

\author{
John M. Brazzel
}

NASA NGR 26004012

The Author is Assistant Professor of Economics and Faculty Research Assistant in the Research Center.

This manuscript was prepared as a part of the research activity under grant NGR 26-004-012 between the Business and Public Administration Research Center, University of Missouri, and the

National Aeronautics and Space Administration

RESEARCH CENTER

School of Business and Public Administration

UNIVERSITY OF MISSOURI

Columbia

March 10, 1967 


\title{
AN ECONOMIC ANALYSIS OF SPATIAL PATTERNS \\ OF RESEARCH AND DEVELOPMENT IN THE \\ PHARMACEUTICAL INDUSTRY*
}

\author{
by
}

John M. Brazzel

\section{I}

Research and development expenditures in the United States have increased substantially in the past decade, rising from approximately $\$ 5$ billion in 1953 to $\$ 19$ billion in $1964[12, \mathrm{pp} .6$ and 9$]$. Perhaps as a reflection of both the magnitude and steady growth of $R \& D$ expenditures, there has been a growing public awareness of, and concern about, the possible effects of $R \& D$ expenditures on the national and regional economies in the United States. One issue that has often been discussed in recent years is the very uneven distribution of $R \& D$ activity among regions [17]. Because industry performs much of the nation's $R \& D$, amounting to 73 percent in $1963[12$, p. 8], the regional distribution of $R$ \& D depends primarily on the distribution of industrial research and thus on individual firm decisions about the best geographic location of research facilities.

This paper is a study of the geographic distribution of research activity in the pharmaceutical industry. We are interested, first, in identifying the existing spatial pattern of pharmaceutical research and, then, in explaining at least some of its causes.

*The research for this paper was supporfed by NASA Research Grant NGR-26-004-012 to the University of Missouri, Columbia, Missouri. 
Although several studies of the economics of research and development from the point of view of the firm or industry have recently become available, they do not develop the locational aspects of industrial research activity. 1

For the purposes of this paper, the pharmaceutical industry is defined to correspond to SIC Industry 283 and thus to include firms that manufacture medicine chemical, biological, and pharmaceutical products. These products are either ethical or proprietary drugs. Ethical products are advertised primarily to the health profession and, for the most part, are available to the public only through written prescription, while proprietary products are advertised and sold directly to the public. Because a major part of the industry's production and sales involve ethical drugs $[13, \mathrm{pp} .53$ and 63$]$, we will view the industry primarily as a producer of ethical products. 2

The pharmaceutical industry is an oligopolistic industry with a few large and many small firms. In 1958 the largest 7 and 15 firms accounted, respectively, for 41 and 61 percent of the industry's sales $[2, p .374]$. Pharmaceutical products may be divided into a number of therapeutic classes. Product competition tends to occur within

${ }^{1}$ See, for example, Minasian [7], Mansfield [6], and Comanor $[2,3]$.

2 The National Science Foundation purportedly takes a similar point of view when gathering data on pharmaceutical R \& D activity, in the sense that firms that are predominantly manufacturers of proprietary drugs are excluded from the published $R$ \& $D$ data $[3$, p. 38]. 
but not among therapeutic markets and it generally takes the form of product differenfiation rather than price competition. Product differentiation in the industry, is achieved both through research expenditures, designed to produce new products or new forms of existing products, and advertising and marketing expenditures. Because pharmaceutical research is intended to achieve product differentiation, research programs favor projects with shorter gestation periods, that is, research on new combinations and dosage forms of existing drugs, rather than new drugs, and applied research and development rather than basic research. This preference for research programs with short gestation periods fends to lead to a high rate of product obsolescence in the industry. As a result, product differentiation cannot be maintained solely through advertising and marketing efforts.

The necessity for sizeable research and selling expenditures in the pharmaceutical industry represents a fairly strong barrier to entry into therapeutic markets. Additional research expenditures are likely to be encouraged where pharmaceutical products are protected by patents since entry into a protected market requires research efforts to circumvent patent protection. On the other hand, the use of cross-licensing agreements for patented pharmaceutical products tends to discourage research expenditures. These agreements maintain barriers to the entry of new producers and at the same time remove the motivation for research to circumvent patents.

In the pharmaceutical industry, then, the research decision is a profitoriented decision designed to give a competitive advantage over other firms and to bar potential competitors. Research expenditures are financed primarily from company, 
rather then federal government, sources of R \& D funds and devoted, in large part, to applied research and development rather than basic research. ${ }^{3}$

If the nature of research in the pharmaceutical industry is shaped by the industry's market structure and the characteristics of its product, it is to be expected that the geographic distribution of pharmaceutical research would also be affected in this fashion. The simplest hypothesis about the location of pharmaceutical research is that research is aftracted toward the location of production. In order to examine the applicability of this hypothesis, the spatial pattern of pharmaceutical R \& D will be compared with the pattern of production.

III

In order to compare the spatial patterns of pharmaceutical research and production, regional data are required. Employment will be used as a measure of both production and research.

Data describing the state distribution of industrial $R \& D$ have only recently been made available by the National Science Foundation [11, pp. 86-88]. However, these data are not available for individual industries.

Pharmaceutical $R$ \& D employment by states was estimated from data published

3 In 1964, 95 percent of the R \& D expenditures of the pharmaceutical industry were financed from company funds, and 87 percent of the $R \& D$ expenditures were used for applied research and development [10, pp. 5 and 9]. 
in the 1956, 1960, and 1965 editions of Industrial Research Laboratories of the United States $[1,9]$. This book lists pharmaceutical laboratories and their locations, types of research, and employment of professional and supporting personnel. A subject index of types of research was used to identify pharmaceutical laboratories in the 1956 and 1960 editions. Many of the labs, listed as performing pharmaceutical research, also were engaged in research on such items as cosmetics, insecticides, and other chemical products. Only those labs with at least 50 percent of their research in pharmaceuticals were considered. In the case of large firms, this usually meant a division of the firm was used. For smaller firms, only labs with more than 50 percent of their activities in pharmaceutical research were counted.

Data from the 1965 edition are much less satisfactory. Industrial laboratories included in this edition are not indexed by type of research. So, only laboratories from the 1956 and 1960 editions that also appeared in the 1965 edition are included in the data from the 1965 edition. In this manner, 54 labs are included from the 1965 edition; this compares unfavorably with 115 labs from the 1960 edition and 98 labs from the 1965 edition. The coverage of pharmaceutical laboratories in the 1965 edition is less complete than in the earlier edition, and it appears to be biased toward the largest firms. Smaller labs listed in earlier editions are not found in the 1965 edition, however, all the pharmaceutical firms in Fortune's 1963-1964 Plant and Product Directory of the 1000 Largest U.S. Industrial Corporations are listed [14]. In the case of a few large pharmaceutical firms, R \& D employment was reported for the entire firm in one or two of the editions, and the employment in labs 
located in different states was not identified. When this occurred, the $R \& D$ employment of the firm was divided among the labs in proportion to the employment shown in another edition. One of the largest pharmaceutical companies, Charles Pfizer and Co., is excluded from our analysis because its employment was not reported by laboratory.

Professional $R$ \& $D$ employment is used as our measure of $R$ \& $D$ activity rather than total $R$ \& $D$ employment. The National Science Foundation reports $R$ \& $D$ employment in terms of the number of full-time-equivalent scientists and engineers. We are limited to the National Science Foundation's measure of industry R \& D employment because of the requirement that the measures of $R \& D$ and industry employment relate to the same definition of the pharmaceutical industry. The only state employment data for the pharmaceutical industry are from the Census of Manufacturers for the years, 1954, 1958, and 1963. The same definition of the pharmaceutical industry is used for both these data and the $R \& D$ data from the National Science Foundation.

The employment data gathered from the 1956, 1960, and 1965 editions appear to include a large part of the industry's professional R.\& D employment. These data are expressed in terms of total numbers employed as compared to the full-timeequivalent measure of the employment of scientists and engineers used by the National Science Foundation. However, by comparing our state R \& $D$ data with the industry data of the National Science Foundation, an impression of the coverage in this analysis of the industry's R \& D employment can be obtained. Following this procedure, 
professional R \& D employment in the pharmaceutical laboratories included for the years 1956, 1960, and 1964 in our figures accounted for approximately 80, 90, and 77 percent, respectively, of the industry's professional employment 4 and was found for 18,22 , and 12 states, respectively.

Professional R \& D employment in the pharmaceutical industry is highly concentrated in a few states in the Midwest and East. The largest three and five states in terms of professional R \& D employment accounted for approximately 50 and 70 percent, respectively, of the industry's professional R \& D employment for each of the years 1956, 1960, and 1964. New York with one-fourth the industry's professional R \& D employment was the first state in each year. New Jersey, Pennsylvania, Michigan, Indiana, and Illinois also appeared among the first five states in the three years. The extent to which pharmaceutical $R \& D$ employment is concentrated among states does not appear to have changed to any large degree from 1956 to 1964.

We have suggested that pharmaceutical research is likely to be attracted toward pharmaceutical production and thus that the geographic patterns of the two types of activity are likely to be similar. In order to determine the applicability of this hypothesis, the coefficient of geographic association and the Spearman rank

4 Because the total industry figures are in terms of full-time-equivalents, these percentages somewhat overstate the actual coverage. The difference is not likely to be more than a few percentage points, however. 
correlation coefficient can be used to obtain some measure of the relationship between the spatial patterns of production and research. Since R \& D employment is included in industry employment, the state distribution of professional R \& D employment is compared with the state distribution of industry employment less professional $R$ \& D employment. This procedure does not cause any significant changes in the results.

The coefficient of geographic association is constructed by subtracting each state's percentage share of professional $R \& D$ employment from its percentage share of total pharmaceutical employment [5, pp. 251-254]. Either the positive or negative differences are then summed and divided by 100. The resulting coefficient can range from zero, if the patferns of research and production resemble each other closely, to one, if the two are completely dissimilar. The coefficients for 1956, 1960, and 1964 were $.26, .20$, and .18 , respectively, indicating that the geographic patterns of research and production are quite similar.

The Spearman rank correlation coefficient is also used to compare the two patterns of employment with generally the same results [16, pp. 202-212]. In this case each state is ranked according to its share of $R$ \& $D$ and industry employment and the two sets of state rankings compared. Rank correlation coefficients of .90 , .91 , and .95 were obtained for 1956, 1960, and 1964, which indicate a high degree - of association between the state patterns of research and production in the pharmaceutical industry. 5

${ }^{5}$ Since we do not know anything about the randomness of the sample of the pharmaceutical laboratories used in this study, no conclusions can be reached about the significance of the correlation coefficients. 


\section{V}

A high degree of association between the geographic patterns of research and production in the pharmaceutical industry is suggested by both measures of association. This does not necessarily indicate, however, that a causal relationship exists between the locations of production and research or that the causality runs in any particular direction. Both research and production activities could agglomerate quite independently of one another.

The existing pattern of pharmaceutical research is likely to have evolved for reasons which are both dependent and independent of the locations of pharmaceutical production. The most important explanations for the location of pharmaceutical research appear to stem from the nature of the research product and the composition of inputs used for the production of pharmaceutical research.

The product of research in the pharmaceutical industry is information which is expected to result, in a reasonably short period of time, in the introduction and manufacture of new pharmaceutical products. Economies are likely to be realized in the process of converting research results into the production of new drugs when communications can be facilitated between those involved in research efforts concerned with product development and those involved in the production process. For this reason, proximate locations of production and research are encouraged by the fact that communication flows tend to deteriorate over increasing distances. 6

${ }^{6}$ The potential advantage of increased flows of information also encourages the combination of research and production in the same corporate structure; see Comanor [4], pp. 16-17. 
The spatial pattern of pharmaceutical research may also be influenced by the composition of inputs used in the research process. Pharmaceutical research is a highly labor-intensive activity; in 1962 and 1963 average company expenditures for $R$ \& D labor services represented approximately 55 percent of their non-capital R \& D expendifures [11, pp. 97 and 101] . Because of the importance of labor in pharmaceutical research, regions with larger supplies of professional and technical R \& D labor skills are relatively more attractive as locations for research facilities, though the opposite direction of causality is also possible. The labor supplies for both pharmaceutical production and research are concentrated in highly urbanized regions. Therefore, the agglomeration of research and production is encouraged by coincident sources of labor, but in this case the two types of activity tend to agglomerate for independent reasons.

Compared with labor, materials and supplies play a relatively small role in the production of pharmaceutical research. In 1962 and 1963, average company expenditures on R \& D materials and supplies represented only 13 percent of their $R$ \& D expenditures [11, pp. 97 and 101]. Because of the relatively small expenditures for these research inputs, the locations of sources of materials and supplies are not likely to have a very strong effect on the spatial pattern of pharmaceutical . research. 


\section{BIBLIOGRAPHY}

1. William W. Buchanan, Industrial Research Laboratories of the United States, Edition 12 (Washington, D.C.: Bowker Associates, Inc., 1965).

2. William S. Comanor, "Research and Competitive Product Differentiation in the Pharmaceutical Industry in the United States," Economica, Vol. XXXI (Nov., 1964), pp. 372-384.

3. William S. Comanor, "Research and Technical Change in the Pharmaceutical Industry," Review of Economics and Statistics, Vol. XLVII (May, 1965), Pp. $182-190$.

4. William S. Comanor, "The Drug Industry and Medical Research: The Economics of the Kefauver Committee Investigations, "Journal of Business, Vol. XXXIX (Jan., 1966), pp. 12-18.

5. Walter Isard, Methods of Regional Analysis: An Introduction to Regional Science (New York: John Wiley \& Sons, 1960).

6. Edwin Mansfield, "Rates of Return from Industrial Research and Development," Papers and Proceedings, American Economic Association, Vol. LV (May, 1965), pp. 310-322.

7. Jora R. Minasian, "The Economics of Research and Development," The Rate and Direction of Inventive Activity: Economic and Social Factors, ed. Richard R. Nelson (Princeton, N.J.: National Bureau of Economic Research and Princeton University Press, 1962), pp. 93-141.

8. Moody's Industrial Manual (New York: Moody's Investors Service, Inc., 1957 to 1965).

9. National Academy of Science, National Research Council, Industrial Research Laboratories of the United States, Editions 10 and 11 (Washington, D.C.: National Academy of Sciences, 1956 and 1960).

10. National Science Foundation, "Basic Research, Applied Research, and Development in American Industry, 1964," Reviews of Data on Science Resources, No. 7 (Jan., 1966). 
11. National Science Foundation, Basic Research, Applied Research, and Development in Industry, 1963 (Washington, D.C.: U.S. Government Printing Office, 1966).

12. National Science Foundation, "Research Funds Used in the Nation's Scientific Endeavor, 1963," Reviews of Research on Science Resources, Vol. I (May, 1965).

13. Pharmaceutical Manufacturers Association, Prescription Drug Industry Fact Book (Washington, D.C.: Pharmaceutical Manufacturers Association, 1965).

14. 1963-1964 Plant and Product Directory of the 1000 Largest U.S. Industrial Corporations (New York: Time, Inc., 1963).

15. Sidney Siegel, Nonparametric Statistics for the Behavioral Sciences (New York: McGraw-Hill Book Company, Inc., 1956).

16. Henry Steele, "Patent Restrictions and Price Competition in the Ethical Drugs Industry," Journal of Industrial Economics, Vol. XII (July, 1964), pp. 198-223.

17. U. S. House of Representatives, Committee on Science and Astronautics, Subcommittee on Science, Research, and Development, Government and Science No. 4, "Geographic Distribution of Federal Research and Development Funds," 88th Cong., 2nd Sess., 1965. 